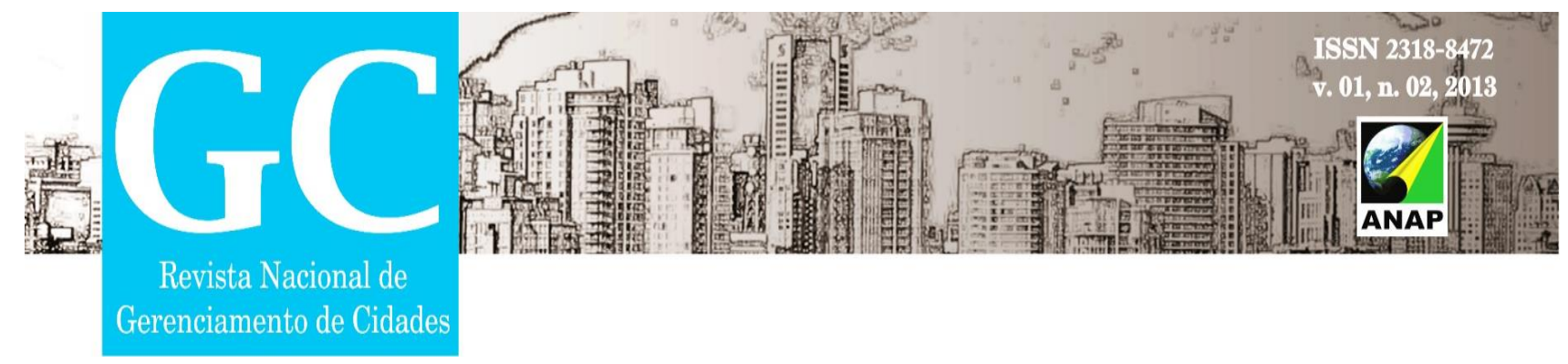

\title{
CONSERVAÇÃO ENERGÉTICA NO PROJETO E NA CONSTRUÇÃO DE EDIFICAÇÕES
}

\author{
Marcela Pádua Silva ${ }^{1}$
}

\author{
Maximiliano dos Anjos Azambuja²
}

\begin{abstract}
RESUMO: A presente pesquisa, realizada em Portugal, tem como objetivo a compreensão dos conceitos de sustentabilidade, construções verdes e planejamento sustentável. Foi realizado um levantamento bibliográfico a cerca do tema, durante o estágio no exterior, buscando compreender mais a fundo tais conceitos. Um estudo de caso foi realizado no bairro da freguesia de Santo Antônio da Charneca, visto como projeto de urbanização sustentável, em Portugal. A pesquisa retrata a compreensão dos preceitos básicos de sustentabilidade e comenta o sucesso da implantação no estudo de caso.
\end{abstract}

Palavras chave: Sustentabilidade. Construções Verdes. Planejamento Sustentável.

\footnotetext{
${ }^{1}$ Arquitetura e Urbanismo, discente UNESP/BAURU, marcelapaduas@hotmail.com

${ }^{2}$ Engenharia Civil, docente UNESP/BAURU, maximilianoazam@feb.unesp.br
} 


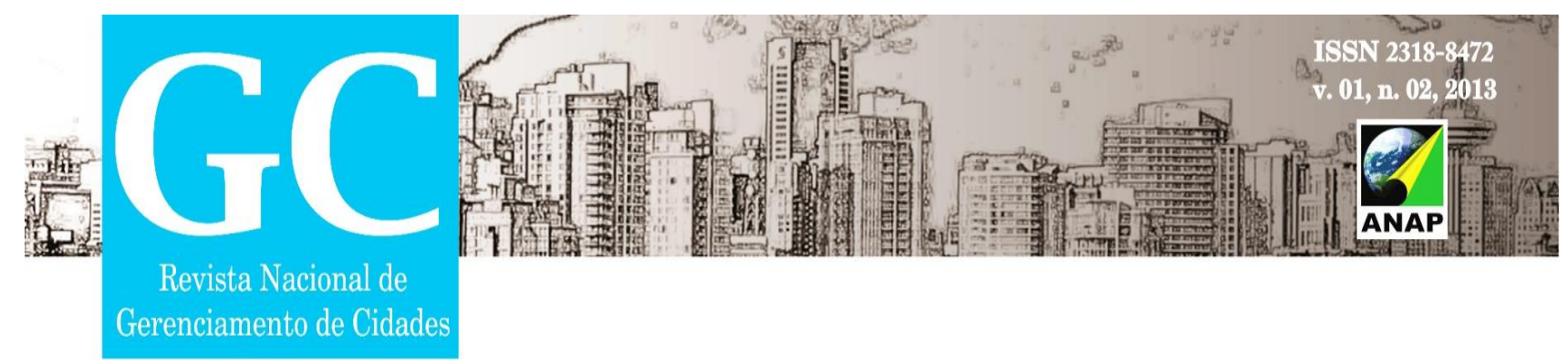

\section{INTRODUÇÃO}

O esgotamento de recursos naturais tem incentivado um maior interesse no mundo industrializado de hoje uma grande atenção para a sustentabilidade do ambiente construído e alternativas sustentáveis para o desenvolvimento e práticas de construção. $\mathrm{Na}$ comunidade das construções verdes, um forte interesse encontra-se em materiais naturais e renováveis para construção que podem ser usados em aplicações estruturais (MAHDAVI, 2012).

A presente pesquisa, realizada em Portugal e financiada pela FAPESP, com a supervisão do Professor Doutor Miguel José das Neves Pires Amado, teve como objetivo o conhecimento da aplicabilidade dos materiais alternativos em construções verdes. Tal trabalho possibilitou maior conhecimento sobre conservação energética das etapas do processo de projeto e técnicas construtivas por meio do intercâmbio da pesquisadora em formação com o grupo de pesquisa do exterior intitulado Grupo de Estudos de Ordenamento do Território do Departamento de Engenharia Civil da Faculdade de Ciências e Tecnologia da Universidade Nova de Lisboa.

A pesquisa do presente estudo, portanto, é descritiva por relatar características da conservação energética das etapas do processo de projeto e técnicas construtivas. Quanto aos meios, a pesquisa é bibliográfica para desenvolver e suportar os objetivos propostos nesse estudo e de campo pela utilização de instrumentos como entrevistas com especialistas sobre o tema e visitas as obras que seguem os conceitos do planejamento sustentável.

\section{DESENVOLVIMENTO}

\subsection{Revisão Bibliográfica}




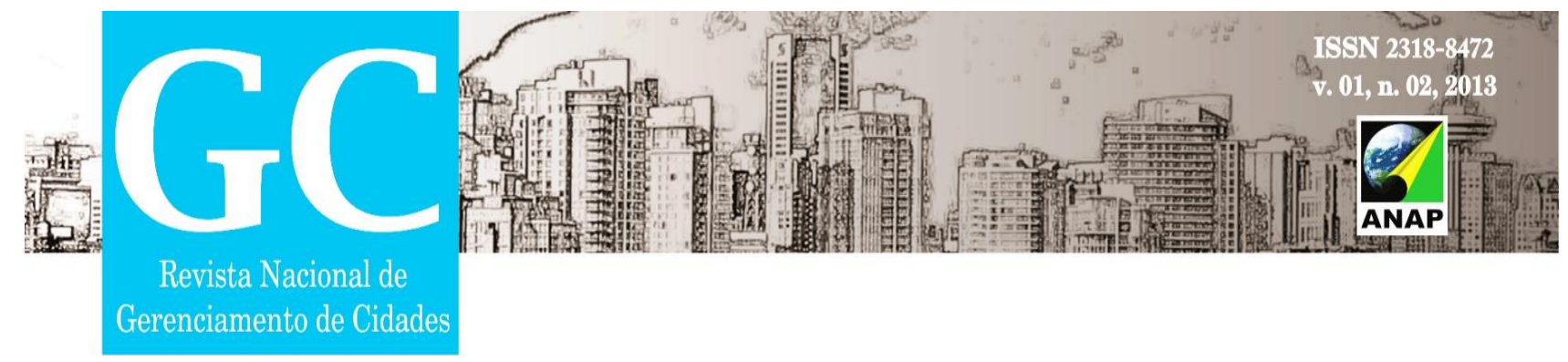

A questão da sustentabilidade, a sua relação com o desenvolvimento e os problemas daí resultantes, foram reconhecidos na década de 60 , muito por influência do livro 'Silent Spring' da autoria de Rachel Carlson, em que pela primeira vez a Primavera aparecia sem flamingos, mortos pela ingestão de alimentos contaminados por pesticidas (Reaes Pinto, 2011).

Desde os anos 70 que a questão ambiental se tornou uma preocupação mundial. O desenvolvimento da sociedade, ao nível populacional e da qualidade de vida, proporcionou o aumento não controlado do consumo dos recursos e materiais disponíveis na natureza (Lucas, 2011). Porém, só veio a ganhar importância e destaque em termos internacionais nos anos 90. Uma das definições mais comuns é a da antiga Primeiroministro da Noruega H. Brundtland: "assegurar os recursos suficiente para as gerações futuras terem uma qualidade de vida similar à nossa". O termo foi firmemente reconhecido na Cimeira Mundial do Rio em 1992, onde foi incluído nos documentos como um alvo a ser atingido pelo Mundo (Pinheiro, 2003).

A partir da altura da realização da Conferência do Rio de Janeiro, adotaram-se, progressivamente, medidas que visam reduzir a poluição gerada, através de uma perspectiva integradora, considerando a totalidade do processo produtivo. Nesta fase, o princípio da prevenção, que preconiza a adoção de medidas preventivas para a proteção do ambiente, assim como o princípio do poluidor-pagador, regem a legislação ambiental (Pinheiro, 2006).

Dois anos mais tarde, em Novembro de 1994, foi efetuada a Primeira Conferência Mundial sobre Construção Sustentável (First World Conference for Sustainable Construction, Tampa, Florida), onde o futuro da construção, no contexto da sustentabilidade, foi discutido. A construção sustentável refere-se à aplicação da sustentabilidade às atividades construtivas, sendo definida (Pinheiro, 2003).

Uma dessas interpretações com especial relevância para o setor da construção é a Agenda Habitat II, que resultou da Conferência das Nações Unidas, em 1996, realizada em Istambul. A Agenda Habitat II demonstra uma preocupação com abrigo para todos e a 


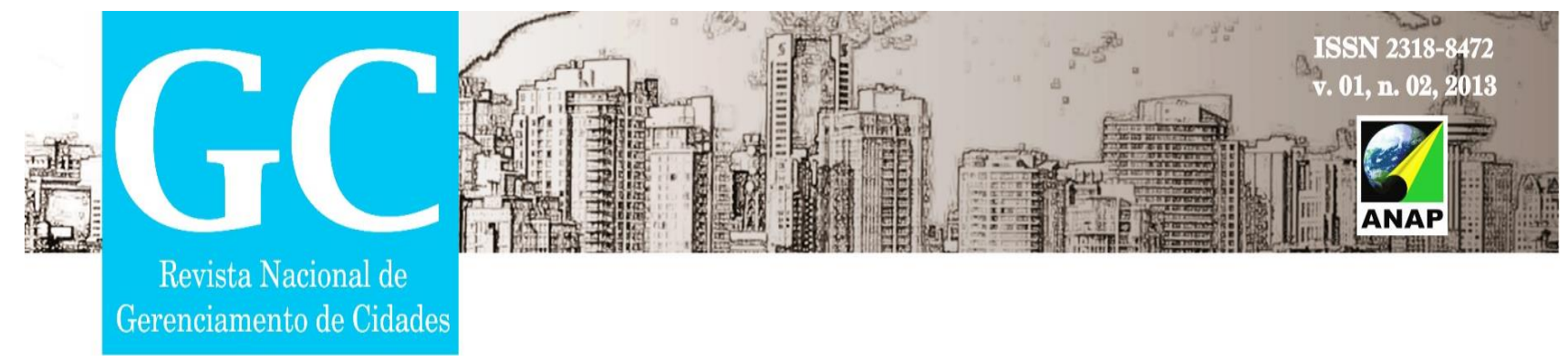

sustentabilidade dos aglomerados humanos e contém diversas secções dedicadas ao setor da construção civil e à forma como os governos nacionais devem encorajar a indústria no sentido da sustentabilidade (Pinheiro, 2006).

A construção é uma das indústrias que mais consome materiais e recursos, sendo a maior parte destes, não renováveis. O agravamento da escassez de recursos aliado à importância de satisfazer as necessidades presentes salvaguardando as gerações futuras está na génese da construção sustentável (Amado et al., 2011).

O setor da construção civil usa em seu processo cerca de $50 \%$ de recursos naturais. O crescimento do aglomerado urbano, a melhoria da qualidade de vida da população e o crescimento do consumo de energia associado, começam no fim do século uma das principais preocupações com o desenvolvimento dos países e as maneiras desse desenvolvimento (Amado, 2002).

Atualmente, o conceito de sustentabilidade é cada vez mais importante, visto que existe uma maior preocupação com a qualidade de vida do ser humano, assim com a melhoria e preservação do meio ambiente, tanto no presente como para o futuro (Amado et al., 2011). A habitação com qualidade é uma necessidade que deve ser satisfeita sem comprometimento dos ecossistemas existentes, levando as empresas a assumirem uma postura ética de valorização do meio ambiente (Florim et al., 2004).

A construção sustentável refere-se à aplicação da sustentabilidade nas atividades construtivas, a qual descreve as responsabilidades da indústria da construção no que respeita ao conceito e aos objetivos da sustentabilidade. (Amado et al., 2011)

Nesse sentido, a Construção Sustentável pode ser entendida "como a que permite a criação e a manutenção do ambiente construído responsável e saudável, assente na exploração, gestão e utilização criteriosa e eficiente dos recursos naturais disponíveis e no respeito pelo meio ambiente e pela ecologia" (Reaes Pinto, 2011).

Para uma construção ser considerada verde, não basta apenas essa ser econômica no quesito energia, ou apenas utilizar materiais que prejudiquem o mínimo 


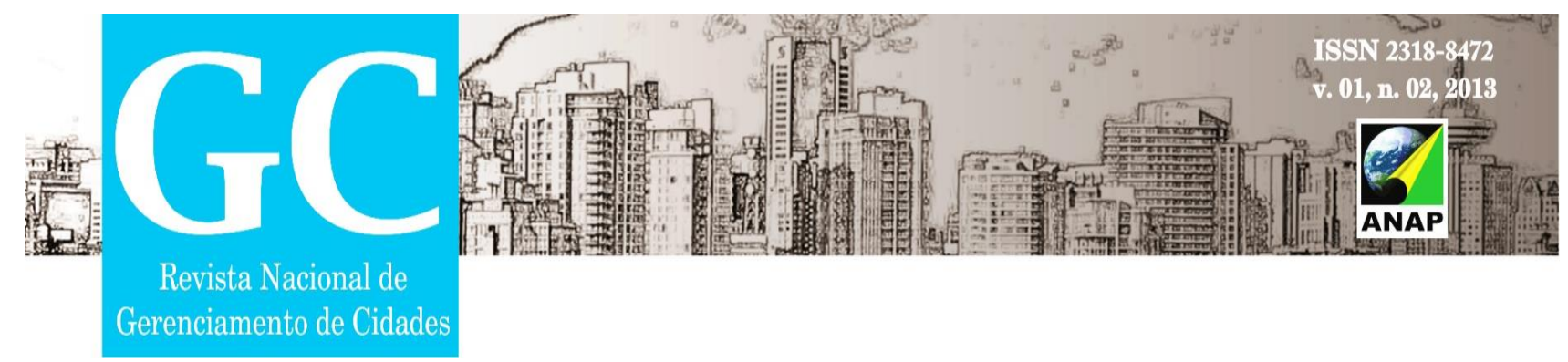

possível à natureza. Uma construção verde deve considerar todo o ciclo de vida do edifício, levando em conta a qualidade ambiental, qualidade funcional e valores futuros.

Segundo John et al. (2005), de acordo com o OCDE Project, os edifícios sustentáveis podem ser definidos como os edifícios que têm impactos negativos mínimos sobre o ambiente natural e construídos, em termos deles mesmos, suas imediações e as configurações regionais e globais. Construções sustentáveis podem ser definidas como práticas de construção, que se esforçam para a qualidade integral (incluindo o desempenho econômico, social e ambiental) de forma ampla. Assim, o uso racional dos recursos naturais e gestão prevista para um edifício apropriado irão contribuir para a poupança de recursos escassos, reduzindo o consumo de energia e melhoria da qualidade ambiental.

$\mathrm{Na}$ fase de projeto é fundamental o estudo de estratégias de forma a encontrar as melhores soluções para o desemprenho do edifício ao longo do seu ciclo de vida. Essa fase é caracterizada pela preocupação com questões relacionadas com conservação de energia e conforto ambiental, portanto é necessário criar um sistema construtivo detalhado com compatibilidade entre várias especialidades do projeto (Lucas, 2011).

De acordo com Lucas (2011), algumas das atividades que são determinadas nsta fase são: a localização, implantação e orientação solar; escolha de materiais de baixo impacto; determinação de eficiência térmica do edifício; ventilação natural; sistemas de recolha de águas pluviais e de reutilização de água.

A sustentabilidade na construção é baseada na ideia de que todo o processo de construção deve ser visto como holístico, que leva em consideração todas as etapas que compõe o ciclo de vida de um edifício e em seguida, em sua faze de projeto, todas as ações que serão realizadas em fases posteriores devem ser pensado e planejado (utilização, manutenção, desativação) (Amado et al., 2011).

É necessário o uso de ferramentas que ajudem a equipe de projeto em sua decisão em todas as dimensões da sustentabilidade (social, econômica, meio ambiente). 


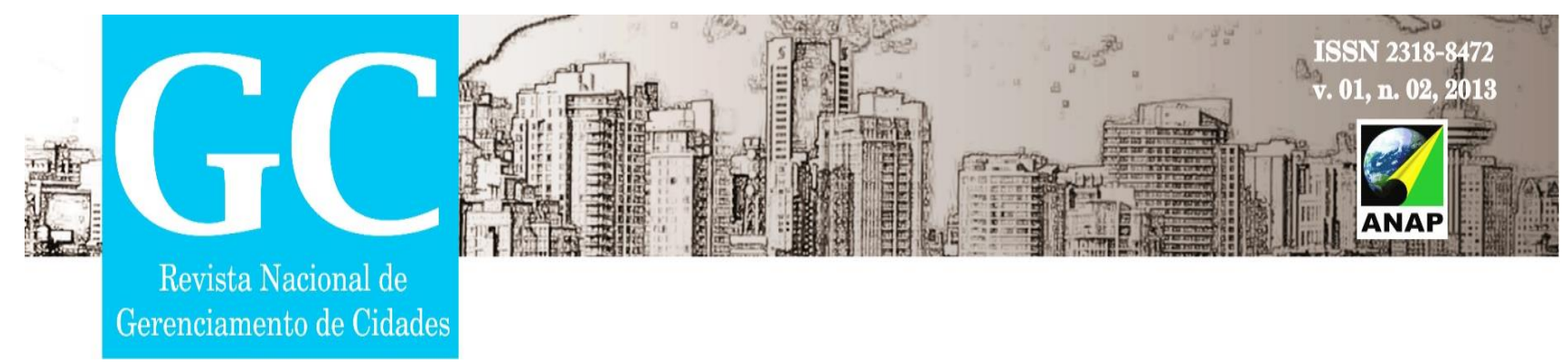

Uma equipe multidisciplinar é também indispensável, para que todo o ciclo de vidado edifício seja pensado.

Muitas cidades pelo mundo têm começado a desenvolver planos urbanos sustentáveis que garantam seus processos de expansão com os desejados resultados sustentáveis. O foco dessas cidades nas áreas de urbanismo sustentável como a estratégia para um crescimento geral e um desenvolvimento econômico enquanto protege os valiosos recursos naturais da degradação (Amado et al., 2011).

As especificações do processo de planejamento sustentável exigem uma visão global com as questões envolvidas, e consequentemente uma concepção holística do projeto. Essas especificações requerem uma metodologia de fácil aplicação em diferentes níveis de intervenção, do projeto- estabelecendo o modelo conceitual para soluções de qualidade urbana, para a construção, definindo o processo tecnológico e os materiais construtivos, em função de minimizar os impactos ambientais e o uso controlando o procedimento de uso dos espaços e recursos (Amado et al., 2007).

Segundo AMADO et al. (2007), esse "novo" método deve ser especificado e facilmente aplicável. Esse método é definido de tal maneira:

- Uso sustentável dos recursos naturais;

- Controle da urbanização desordenada;

- Satisfação das necessidades da população e expectativas;

- Redução do desperdício e consumo;

- Promoção da economia local e empregos;

- Preservação natural, econômica, social e diversidade cultural;

- Promoção da eficiência energética, e uso de energias renováveis;

- Encorajamento de novos modos de mobilidades;

- Envolvimento da população local no processo de planejamento urbano.

A partir desse método deve também resultar a promoção de mudanças fundamentais dos princípios do uso da terra, que fornecem: 


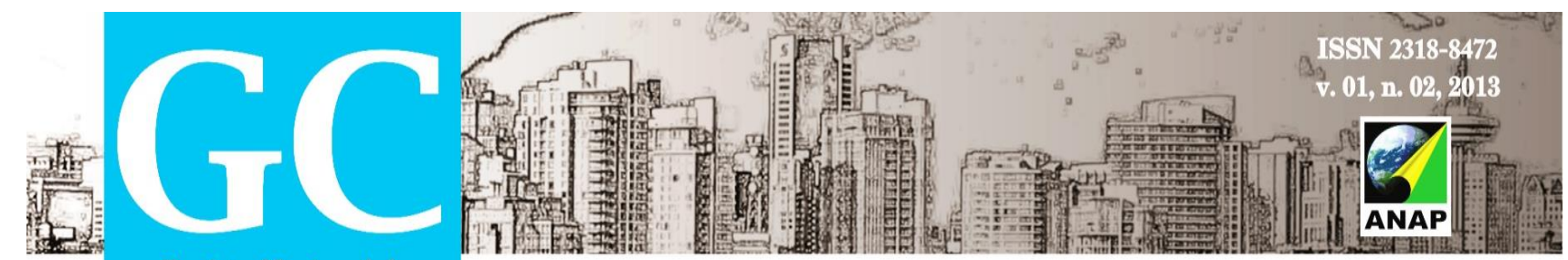

Revista Nacional de

Gerenciamento de Cidades

- Bem estar social- incluindo lazer em áreas naturais;

- Eficiência ambiental- minimizando os impactos ambientais;

- Eficiência econômica- garantindo a durabilidade dos sistemas urbanos;

- Incluir o desenho urbano, criando condições de total acessibilidade nas áreas urbanas.

O projeto de construção sustentável é, portanto, a integração entre o pensamento do arquiteto com recursos de engenharia elétrica, mecânica e estrutural. Além de expressar a preocupação estética tradicional de aglomeração, a orientação, escala proporcional, textura, sombra e luz, a equipe de projeto de instalação precisa se preocupar com os custos de longo prazo: ambiental, econômico e humano (JOHN et al., 2005).

\subsection{Estudo de caso}

Para o desenvolvimento do trabalho, foi realizada a visita em um bairro sustentável, que teve um projeto de Urbanização, nomeadamente o lote 7, localizado na Quinta do Visconde, freguesia de Santo António da Charneca, no concelho do Barreiro.
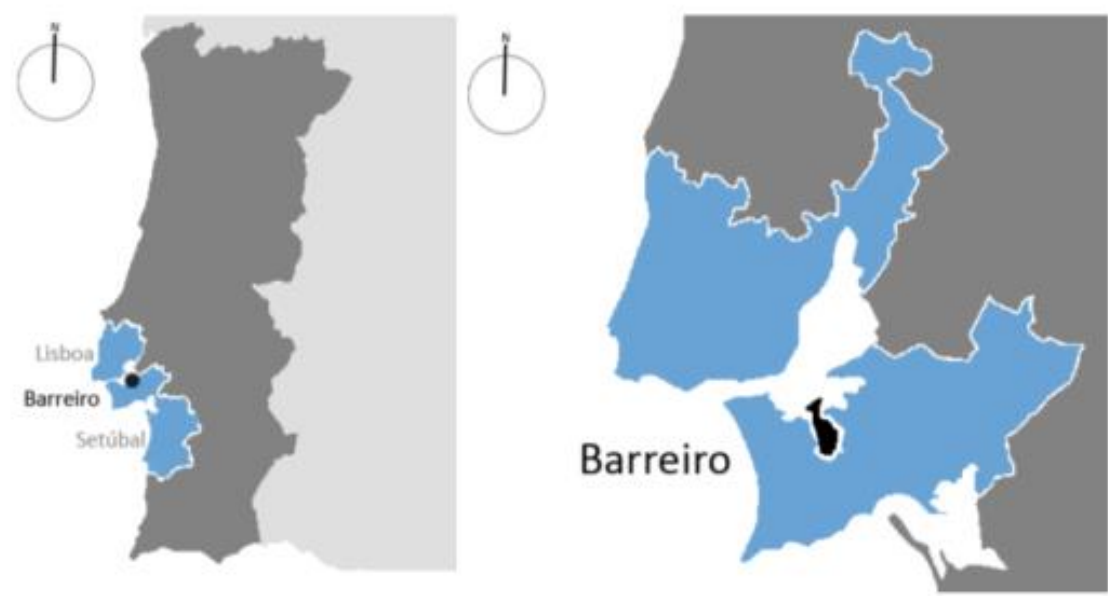


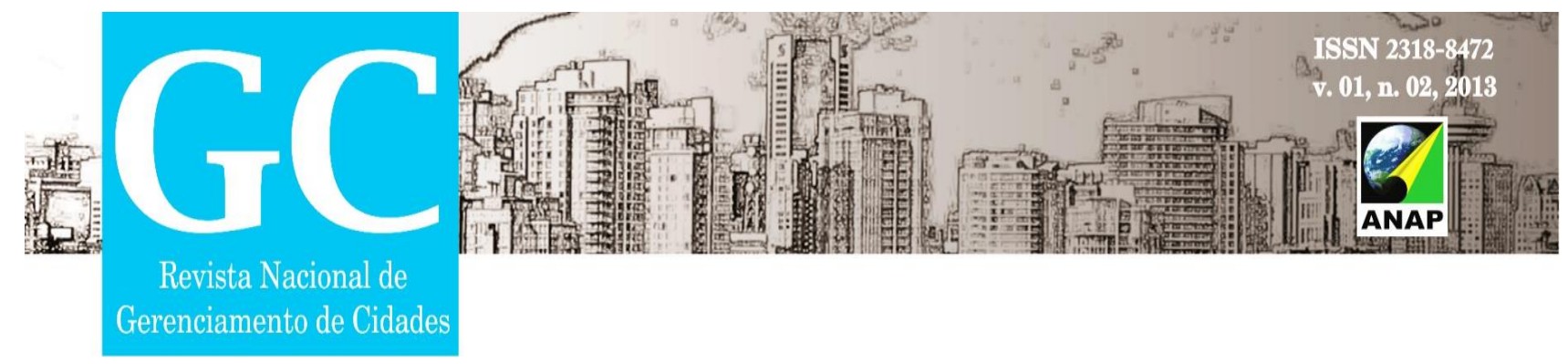

Figura 1. Localização do Barreiro em Portugal e Localização do Barreiro na AML Fonte: Ramalhete et al.,2013

Segundo Ramalhete et al.(2013), o conselho do Barreiro, devido à forte proximidade com Lisboa, está a ser alvo de um conjunto de ações de desenvolvimentos das infraestruturas, especialmente no que se refere às acessibilidades. $O$ conselho é caracterizado por uma zona urbana a norte e por uma zona periurbana e rural a sul, sendo que os equipamentos de apoio à população estão ainda polarizados na freguesia do Barreiro. O Barreiro é ainda marcado por características ímpares em termos de vivência social, com uma forte tradição associativa, tendo mais de duzentas associações e coletividades, que promovem o desporto, cultura e solidariedade social, um pouco por todo conselho.

A legislação em vigor foi implementada com uma perspectiva sustentável referente ao edificado, alterando, por via da lei, as concepções de construção, procurando soluções viáveis em termos de eficiência energética e, consequentemente, viáveis em termos econômicos.

A obra em estudo é o empreendimento Casas de Santo Antônio, no conselho do Barreiro, promovido pela empresa GoGui Construções Ltda., e projetado e desenvolvido pela empresa PROGESTO- Gabinete Técnico de Gestão, Arquitetura e Planejamento Ltda.

O projeto da urbanização foi orientado por uma estratégia de desenho solar passivo ao nível do urbanismo e da arquitetura, procurando uma vivência sustentável do próprio empreendimento no local da implantação. O conjunto edificado foi criteriosamente relacionado com a envolvente que, por sua vez, apresentava um conjunto de características especiais, como sendo o caso da proximidade com o IC21 e simultaneamente com a Mata Nacional da Machada.

O projeto baseia-se principalmente na promoção e no desenvolvimento de um desenho urbano que apresente um novo tipo de urbanidade e um novo modelo de planear e construir. Ao nível urbano, o desenho de soluções passivas passou pela investigação de 


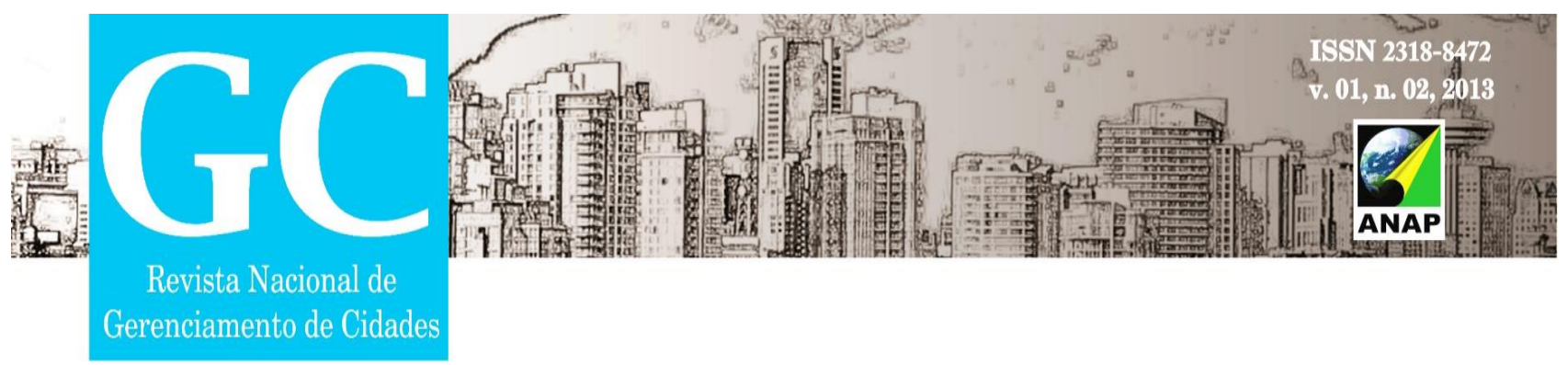

soluções adequadas ao nível das dimensões, geometria, orientação dos edifícios e dos arruamentos, densidade habitacional, tipo de uso e porcentagem de área impermeabilizada pelas construções (Ramalhete et al., 2013).

A orientação dos arruamentos, em conjunto com a disposição dos edifícios foi uma das estratégias adotadas para assegurar o conforto no espaço público no que se refere a: equilíbrio da temperatura; proteção dos ventos predominantes em determinadas direções, garantindo a renovação do ar nos espaços interiores e, simultaneamente, protegendo o edifício e a via dos ventos dominantes. O tipo de espécie arbórea pode variar consoante a orientação dos ventos face aos edifícios (Ramalhete et al., 2013).

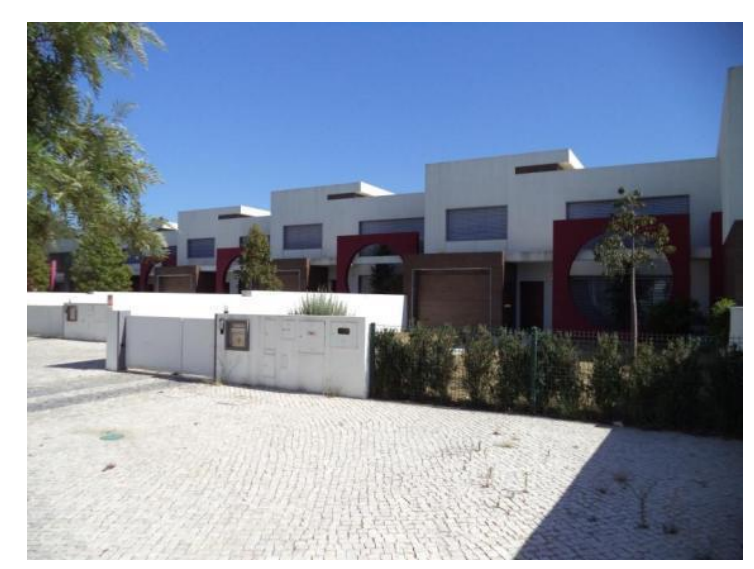

Figura 2. Casas de Santo António Fonte: $\mathrm{O}$ autor

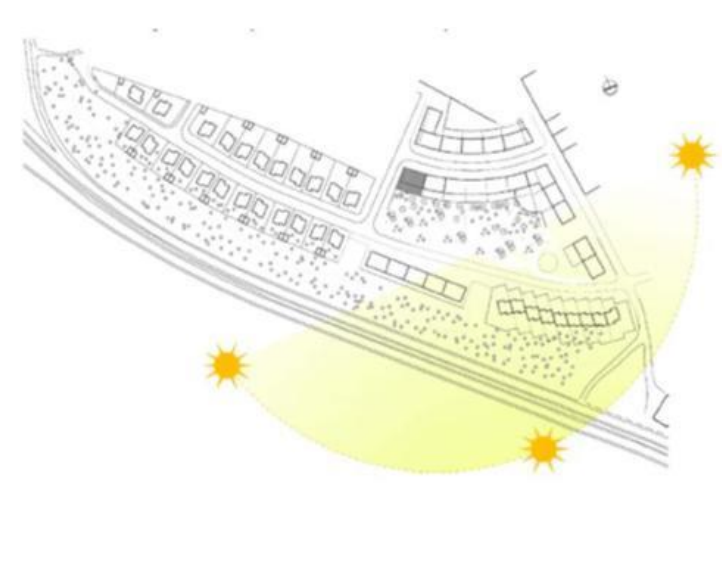

Figura 3. Orientação Solar da urbanização com a demarcação do lote 7.

Fonte: Ramalhete et al., 2013

Em relação ao ruído e ao "conforto visual", levando-se em conta que o projeto encontra-se próximo a uma rodovia, a solução passou por uma estratégia de reflorestamento na medida em que foi implantada uma "barreira verde" composta por pinheiros bravos e arbustos rasteiros entre a urbanização e o eixo viário.

A questão da permeabilização da zona de intervenção foi importante devido à proximidade da Mata Nacional da Machada, integrada na Reserva Natural Local do Sepal 


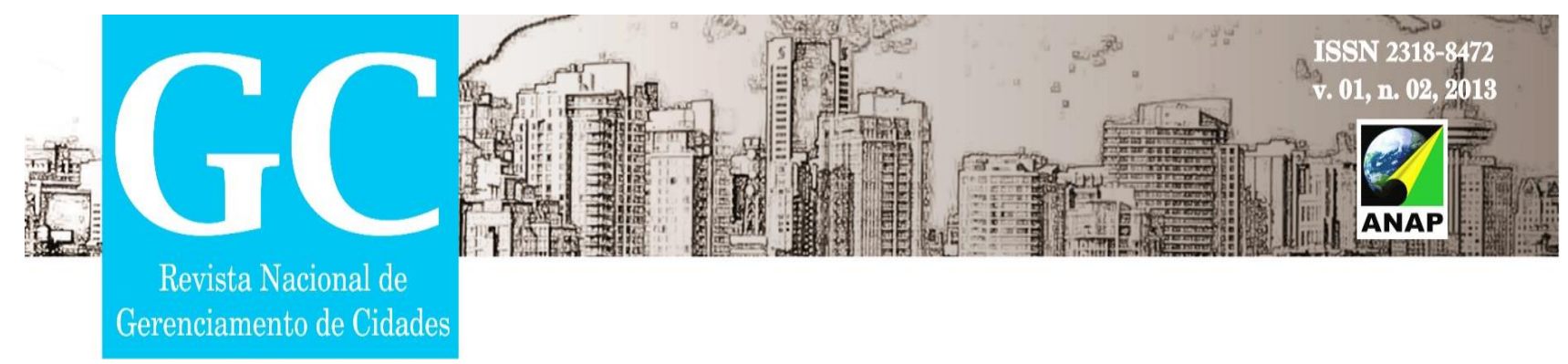

do Rio Coina e Mata da Machada (Ramalhete, 2013). Foi proposto um sistema de recuperação de águas pluvial, contribuindo para o equilíbrio natural da Mata da Machada. O sistema consiste na captação das águas pluviais que são encaminhadas para um reservatório localizado na mata para a utilização da fauna local.

Em termos de permeabilização da área urbanizada foram adotadas outras soluções passivas tal como o encaminhamento de águas (pendente) da praça central ajardinada, que permite a infiltração de um depósito comum, e a implementação de uma malha permeável em cimento nas zonas de estacionamento (grelhas de enrelvamento) (Ramalhete et al., 2013).

O edifício designado como Lote 7 da Urbanização Casas de Santo António, com uma área de $381,65 \mathrm{~m}^{2}$, sendo a área de implantação de $243,18 \mathrm{~m}^{2}(63,71 \%$ da área do lote). A iluminação natural é garantida com intensidade apropriada à função e uso no interior do edifício, sempre que as condições atmosféricas e permitam exclusivamente através da radiação solar direta. Proteção solar passiva e ativa também se faz presente e necessária para o controle da intensidade e da luminosidade apitada pelos vãos envidraçados (Ramalhete et al., 2013).

Em relação à ventilação, como o lote está localizado de forma a receber do vento preferenciais nas direções NO e SE, a solução passa pela orientação de vãos a norte, para que no verão receba menos radiação e propicie a circulação e ar fresco, e a sul, para que no inverno receba mais radiação solar para o aquecimento dos espaços. A volumetria proposta tende a possibilitar a insolação franca em todos os lotes, bem como uma exposição aos ventos predominantes de verão. 

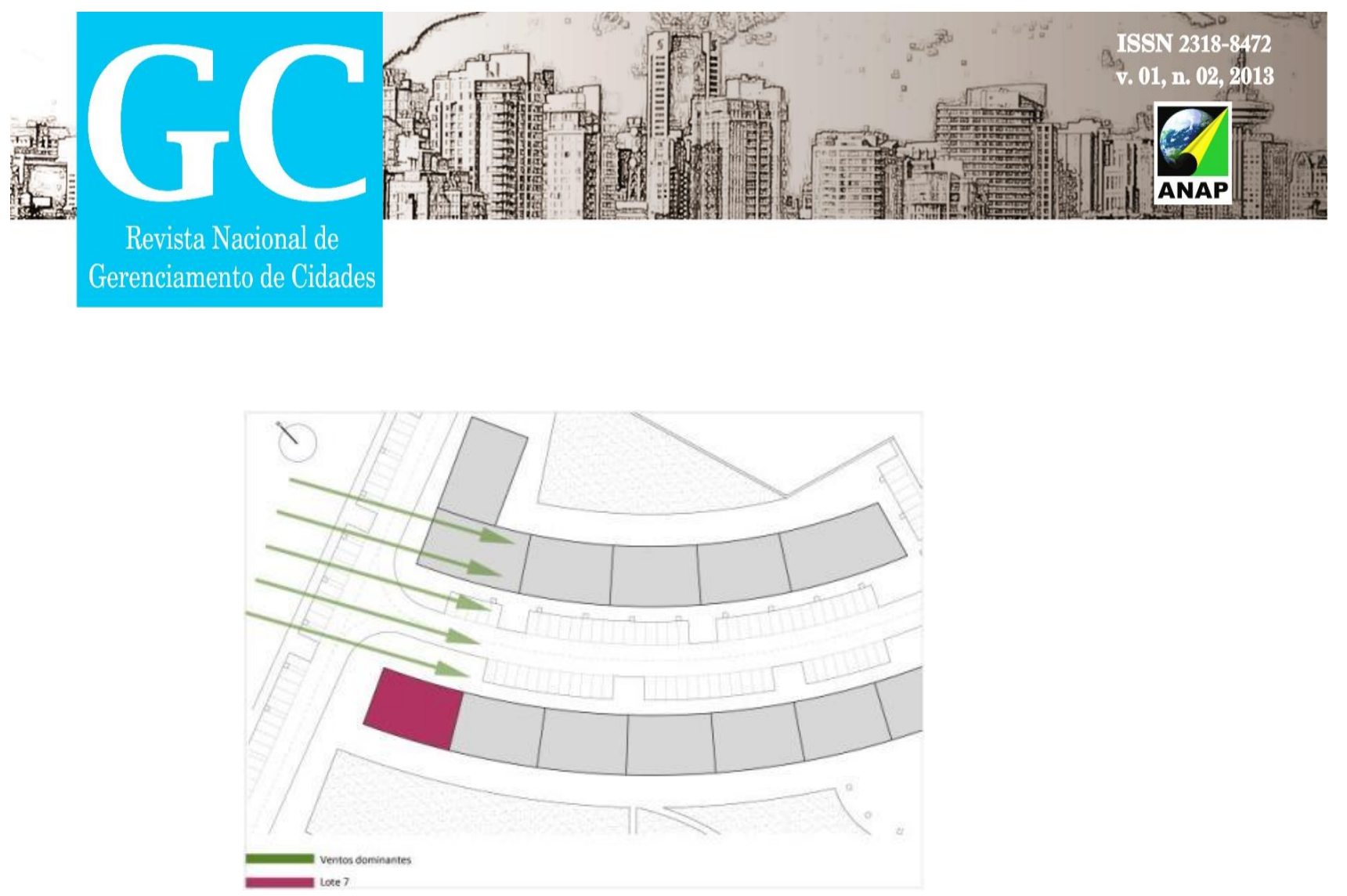

Figura 1. Ventos dominantes da região da região

Fonte: Ramalhete et al., 2013.

Outra característica do projeto é a versatilidade da construção que procura minimizar remodelações e consumo de recursos adicionais, tendo em conta que as necessidades de espaço e de uso podem ser alteradas com o tempo.

Há também uma instalação de redes de águas residuais e águas pluviais que servem todas as instalações sanitárias e a cozinha da habitação.

A proposta é se utilizar aparelhos de iluminação equipados com lâmpadas de baixo consumo, dotados de balastros eletrônicos de alta-frequência, para redução de consumos e diminuição da trepidação da luz, e como já foi dito, se beneficiar também da luz natural do ambiente que entra pelas aberturas. O sistema de iluminação dos espaços de circulação, corredores de distribuição e instalações sanitárias é exterior e acionado com sensores de presença para permitir o desligar parcialmente as lâmpadas em períodos de não utilização, e assim economizar energia (Ramalhete et al., 2013).

Com a intenção de incentivar a separação do lixo doméstico para a reciclagem, foi projetada, na habitação, um espaço na cozinha com móvel adaptado à separação do lixo por qualidades. 


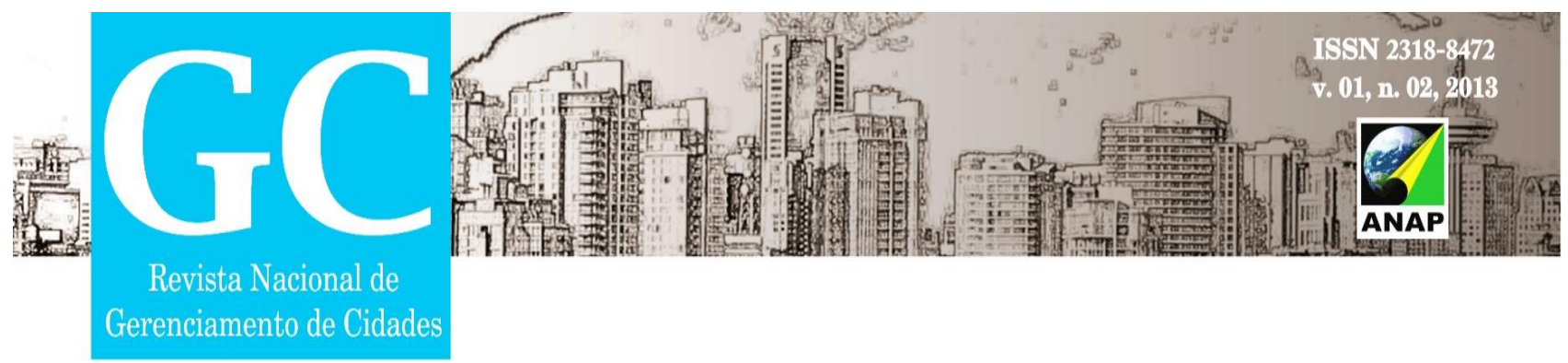

O pavimento flutuante em pranchas de madeira constitui um acumulador de calor natural devido ao laminado de madeira (Acer TARKETT com acabamento em verniz de poliuretano mate) conjugada com uma película de polietileno de $4 \mathrm{~mm}$, representando uma condutibilidade térmica baixa de $0,07 \mathrm{~m}^{2} \mathrm{~K} / \mathrm{W}$.

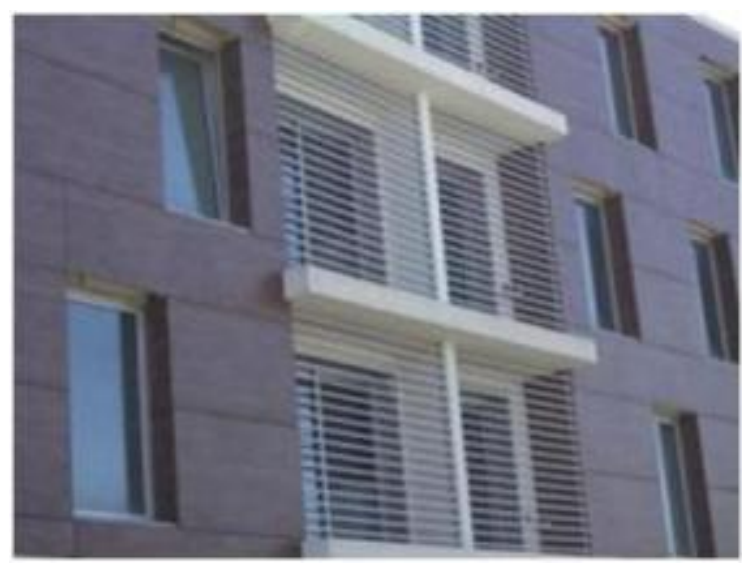

Figura 5. Detalhe das pranchas de madeira

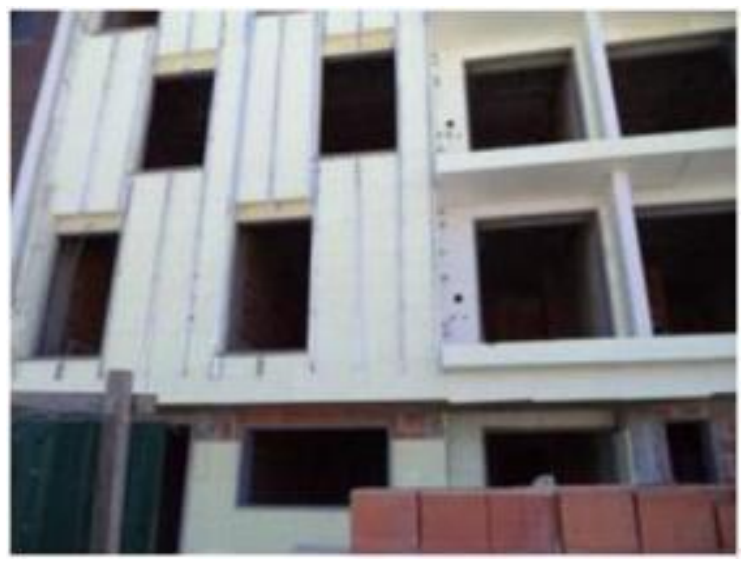

Figura 6. Detalhe do isolamento Térmico no exterior

Fonte: $\mathrm{O}$ autor

O desenho de soluções solares passivas para condições de verão visa à eliminação de calor e o sobreaquecimento do espaço interior. Como tal, baseia-se em métodos de ventilação passiva e na implementação de elementos de sombreamento que podem ser arquitetônicos ou naturais. Todos os elementos construtivos têm um efeito no sobreaquecimento: a cobertura, as paredes, os vãos, a forma do edifício e a cor das fachadas. Os vãos são os elementos que requerem uma abordagem mais cuidada na medida em que recebem radiação direta, assim como a cobertura, que recebe o maior número de horas de sol. Contudo, o estudo dos vãos deve ser global, pois no Inverno são fundamentais para a captação de radiação solar.

Como ocorre no desenho solar passivo para as condições de inverno, nas soluções para as características de verão o tipo de vidro e caixilharia são igualmente 


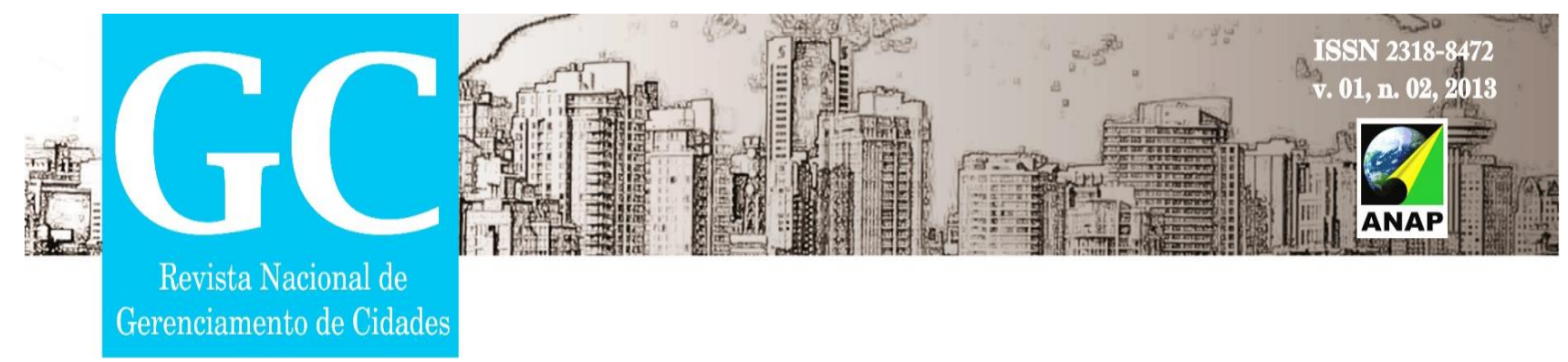

importantes. Nas condições de Verão, de modo a complementar a ação do vão envidraçado, foram incorporados pelo exterior, estores de lâminas metálicas, que permite ao utilizador controlar a luminosidade e a visibilidade, controlando a luminosidade para garantir o conforto visual e térmico.

Para auxiliar no conforto Térmico, nas paredes exteriores foram implantados revestimentos através de um sistema de placas TRESPA-METEON com resistência aos raios UV e alterações bruscas de temperatura.

A eficiência energética de um edifício é consequência de um desenho solar passivo que se adapte às condições de Verão e de Inverno, mas também à implementação de sistemas de produção de energia renováveis e não poluentes como sendo o caso de painéis solares (Ramalhete et al., 2013).

No projeto do Lote 7 , foi prevista a implementação de painéis solares na cobertura no que refere à produção de energia para águas quentes sanitárias. O uso dos painéis reduziria em cerca de $41 \%$ dos consumos diários de energia.

Além do conforto térmico, uma das preocupações foi o conforto acústico, devido ao fato da obra se localizar próximo à IC21, uma autoestrada que passa ao lado do bairro e tem um alto fluxo de automóveis. O revestimento com painéis TRESPA-METEON e o sistema de isolamento pelo exterior DRYVIT de $60 \mathrm{~mm}$, também ajudam na redução da transmissão de som através da criação de uma barreira que aumenta as propriedades acústicas de absorção de som em $6 \mathrm{~dB}, 50 \%$ de nível do ruído interior.

Segundo Ramalhete et al.(2013), a Análise do ciclo de vida do edifício é um dos princípios importantes para a eficiência (que engloba a eficiência energética e a durabilidade) e funcionalidade do próprio edifício, ou seja, esta análise centra-se em todas as fases do processo, desde o programa, projeto, construção, manutenção, adaptabilidade do uso e uma possível desconstrução do edifício e, como tal, a gestão e reciclagem dos resíduos.

Durante a elaboração do programa foi realizada uma análise socioeconômica e demográfica do local, mostrando que o programa de habitação no local viria a impulsionar 


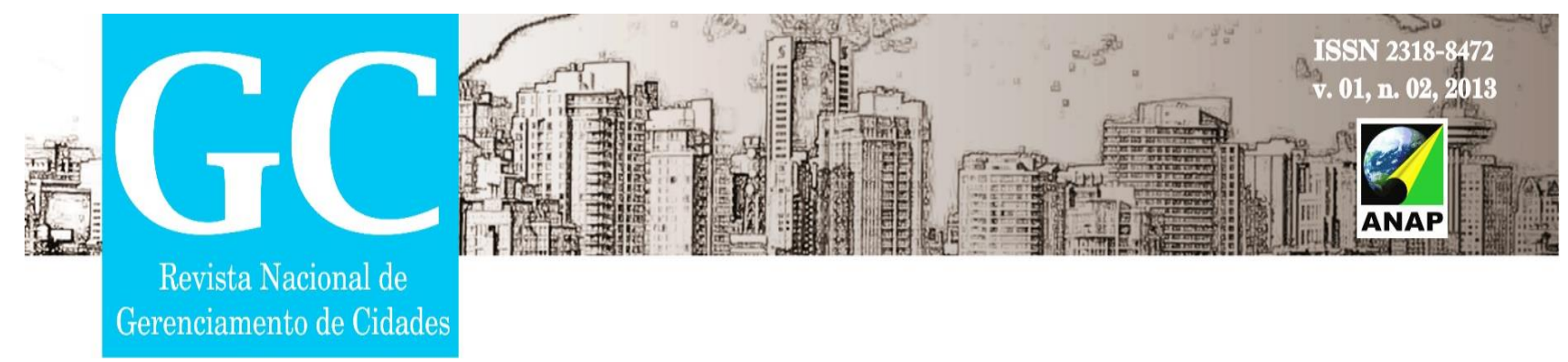

o desenvolvimento do conselho que, caracteriza-se como uma zona "dormitório" da cidade de Lisboa. Levando-se em conta o posterior desenvolvimento da região, foi importante flexibilizar o uso dos espaços. A caracterização da comunidade foi também um fator importante no que diz respeito às normas de acessibilidade e segurança. Nessa etapa foram definidos também as atividades e os usos, assim como seus impactos na dinâmica socioeconômica do local de implantação.

$\mathrm{Na}$ fase do projeto foi feita a seleção dos materiais e o estudo da sua energia incorporada, buscando utilizar materiais de baixo impacto ambiental. A durabilidade do material também é considerada.

O projeto Casas de Santo Antônio, nomeadamente o lote 7, complementou a questão da durabilidade dos materiais através da criação de um Manual de Utilização e Manutenção da Habitação para o futuro utilizador, permitindo que o utilizador tire o melhor partido da sua habitação de forma eficiente. Sobre a gestão dos resíduos, foram utilizados materiais recicláveis ou reutilizáveis.

\section{CONCLUSÃO}

A questão da Sustentabilidade se torna cada vez mais indispensável no setor da construção civil e vem ganhando cada vez mais espaço. Com o grande consumo de recursos e o mau uso de materiais, novas tecnologias, técnicas e soluções são essenciais.

Deve-se ter cautela ao nomear um edifício de Sustentável. A Sustentabilidade está além dos selos dados por algumas instituições. Para ser sustentável o edifício deve reduzir impactos desde sua concepção até o fim de sua vida útil. Não basta apenas reduzir energia durante a sua utilização. Os materiais utilizados para sua construção devem ser pensados, tal como deve se ter a preocupação da energia incorporada a tais materiais, dando preferência para materiais locais, renováveis e de preferência que possam ser reciclados ou reutilizados após o fim da vida do edifício. É essencial a preocupação, durante o projeto, para que o edifício tenha ventilação natural, orientação solar adequada, 


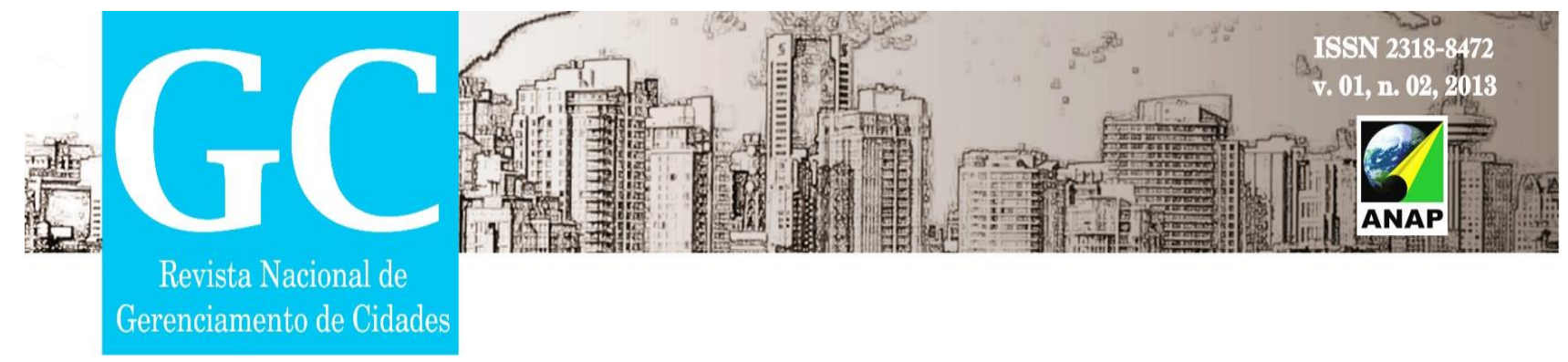

para que assim, garanta o conforto térmico do edifício. Além de claro, tentar reduzir o seu consumo energético. $O$ reaproveitamento de água também é de grande importância para se alcançar a autossuficiência da construção.

A Sustentabilidade deve buscar o equilíbrio. Não somente ecológico, mas social e econômico. Deve-se levar em conta a cultura e modo em que vive a população local, para que o edifício possa fazer parte do dia a dia do local. É essencial que não só o edifício seja sustentável, mas todo o seu entorno, buscando solucionar problemas de trânsito, de falta de áreas verdes e trazendo uma real qualidade de vida para a região.

\section{AGRADECIMENTOS}

Agradeço pelo período de bolsa concedida, processo no 2013/07848-5, Fundação de Amparo à Pesquisa do Estado de São Paulo (FAPESP). Ao supervisor do estágio no exterior Professor Doutor Miguel José das Neves Pires Amado pelo acolhimento. As opiniões, hipóteses e conclusões ou recomendações expressas neste material são de responsabilidade dos autores e não necessariamente refletem a visão da FAPESP.

\section{REFERÊNCIAS}

AMADO, M.; FREITAS, J.; LOPES,T.; Green Build Design Process. In: World Sustainable Building Conference, Helsinki, Finland, 2011.

AMADO, M.;POGGI, F.; Towards Solar Urban Planning: A New Step for Better Energy Performance. Energy Procedia, 00, p.1-13, 2011.

AMADO, M.P.; PINTO,A.J.; SANTOS, C.V.; CRUZ, A.; Methods in sustainable urban process. In: BRAGANÇA,L.; PINHEIROS, M.D.; JALALI,S.; MATEUS, R.; AMOÊDA,R.; GUEDES, M.C.; Portugal SBO7 Sustainable Constructions Materials, IOS Press, 2007, p. 694- 701. 


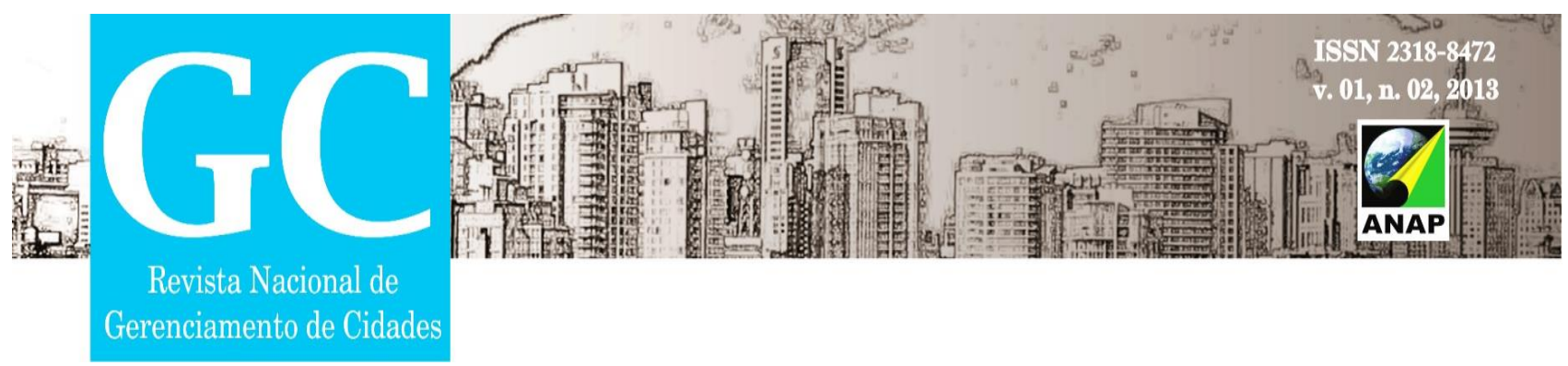

AMADO, MIGUEL P.; et al. Sustainable Building Process. In: XXXV IASH World Congress on Housing Science - planning, design, construction and performance, volume 1 of World Congress on Housing Science (CD-ROM), page 65, Ron Wakefield; Nick Blismas. Melbourne - Austrália, RMIT University, 2007.

AMADO,M.; Energy Conservation in Habitation Buildings and the Level of Environmental Comfort. In: IAHS World Congress on Housing, 30, Coimbra, 2002, p. 110.

CHWIEDUK, D.; Towards sustainable-energy buildings. In: Aplied Energy, 76, p. 211217, 2003.

FLORIM, L.C.; QUELHAS, O.L.G.; Contribuição para a construção sustentável: Características de um projeto habitacional eco-eficiente. Engevista, v.6, n.3, p.121132, 2004.

JOHN,G.; CLEMENTS-CROOME, D.; JERONIMIDIS,G.; Sustainable building solutions: a Review of Lessons from the Natural World. Building and Environment,40, p.319328, 2005.

LUCAS, V.S.; Construção Sustentável- Sistema de Avaliação e Certificação. Lisboa, 2011. 197p. Dissertação de Mestrado- Faculdade de Ciências e Tecnologia- Universidade Nova de Lisboa.

MAHDAVI, M.; CLOUSTON, P.L.; ARWADE, S.R. A low-technology approach toward fabrication of Laminated Bamboo Lumber, Construction and Building, n. 29, p.257262, 2012

PINHEIRO, M.D.; Ambiente e Construção Sustentável, Lisboa: Instituto do Ambiente, 2006, 243p.

PINHEIRO, M.D.; Construção Sustentável- Mito ou realidade?. In: Congresso Nacional de Engenharia do Ambiente, 7, Lisboa, 2003, p 1-10.

RAMALHETE, I., SANTOS,J., BERNARDES,V. Relatório de Caracterização e diagnóstico: EcoBairro Barreiro. Lisboa: Faculdade de Ciências e Tecnologia da Universidade Nova de Lisboa, 2013.

REAES PINTO;A.; "A escolha dos Materiais para a construção sustentável”. Revista Arquitectura Lusíada,N.3 (2 semestre 2011): p. 77-82, 2011.

REAES PINTO;A. ; "A escolha dos Materiais para a construção sustentável”. Revista Arquitectura Lusíada,N.3 (2॰ semestre 2011): p. 77-82, 2011. 